\title{
(Mis)alignment in Relation to Written Corrective Feedback: The Teachers' Beliefs and Practices vs the Students' Preferences in an EFL Context
}

\author{
Soufiane Trabelsi \\ Higher Institute of Business Administration of Sfax, University of Sfax, Sfax, Tunisia \\ Email address: \\ Sofientt2000@yahoo.fr \\ To cite this article: \\ Soufiane Trabelsi. (Mis)alignment in Relation to Written Corrective Feedback: The Teachers' Beliefs and Practices vs the Students' \\ Preferences in an EFL Context. International Journal of Language and Linguistics. Vol. 9, No. 1, 2021, pp. 6-16. \\ doi: $10.11648 /$ j.ijl1.20210901.12
}

Received: December 29, 2020; Accepted: January 19, 2021; Published: February 23, 2021

\begin{abstract}
This paper, which investigates written corrective feedback (WCF) in the context of English as a Foreign Language (EFL), will address two research questions: (a) to what extent are the teachers' beliefs and practices regarding the provision of WCF on the students' EFL writing aligned?; (b) to what extent do the students' preferences match the teachers' practices regarding WCF? The participants of the study were nine writing teachers and their 75 pre-intermediate and intermediate students in one General Foundation Programme (GFP) in Oman. Semi-structured interviews, classroom observation, student text analysis, and student focus groups were employed as the research instruments of the study to attempt to answer the research questions. The study revealed more areas of misalignment than alignment between the teachers' beliefs and practices related to WCF. The areas of misalignment are related to the writing of praising comments, redrafting, the amount of feedback, the explicitness of feedback and the focus of feedback, whereas the areas of alignment are related to the identification and the correction of errors. In addition to that, the findings indicated that there were more areas of congruence than incongruence between the students' preferences and the teachers' beliefs and practices regarding WCF. As for the areas of congruence, they are related to the explicitness of feedback, the amount of feedback, the source of feedback, and the correction of errors. The areas of incongruence, however, are related to the focus of the feedback and the writing of praising comments. The paper concluded by providing some implications for pedagogy related to WCF.
\end{abstract}

Keywords: (mis)alignment, (in)congruence, Beliefs, Practices, Written Feedback, Error Correction, Peer Feedback

\section{Introduction}

Exploring EFL teachers' beliefs and practices as well as their students' preferences related to WCF is considered as an essential source of information to improve foreign and second language learning and teaching. The main objective of the study is to find out the extent to which the teachers' WCF practices meet their students' needs and preferences. In investigating the teachers' thoughts and actions regarding WCF as well as the students' preferences in terms of WCF types and their perceptions of their teachers' WCF practices then comparing them with the literature and the main findings of Second Language Acquisition (SLA) and WCF research, the researcher will attempt to explore if WCF in the Omani EFL context is in line with the latest research and best practices and approaches. In other words, the objective is to make sure that WCF is suitably geared towards writing skill development and writing accuracy.

This study is justified by the importance of writing in the Omani context as well as the role feedback may play in the development of student writing. The practice of providing feedback to students reveals that teacher written feedback is worth researching, as it is commonly used in this context. Findings of this study will contribute to the debate on WCF and advance it forward.

Most of the literature on the beliefs and practices related to WCF has only considered either teachers or students alone. However, the current study examines and compares both parties, which provides a new insight into teachers' beliefs and practices and students' preferences. Understanding what 
teachers and students know and think, and how that has an impact on teachers' instructional practices, can give more insights on the problems teachers face (while they provide feedback) and students have (in coping with their teacher's comments). This may also help to develop better support for teachers in terms of training and development, the design of teacher-friendly materials, and so forth-thus ultimately producing more effective teachers and teaching. This will also allow us to account for any incongruence that my exist between students' preferences and teachers' perceptions of students' needs, which in turn could be useful for designing a needs analysis' procedure, to avoid any potential misunderstanding between both parties.

\subsection{Feedback in the Teaching of ESL/EFL Writing}

It is because of the existence of several research studies investigating different types of feedback and their impacts on student writing which has made many scholars and researchers believe that feedback plays influential roles in the writing process. Many researchers consider WCF as a clear, prioritised and selective way of guiding and helping students master and correct their mistakes [5]. Providing feedback on students' writing is viewed as an important pedagogical practice for teachers, who have the hope that the feedback will enable their students to improve their writing skills and language accuracy $[19,6]$.

Carless [9] adds that as soon as students receive feedback during the writing process, it will become clear for them how well they are performing and what needs to be done in order to improve. Brookhart [8] maintains that feedback can serve as an assessment on how well the students perform their work or their accomplishment of a given task since feedback is intended to help students fill the gap between their actual ability and the desired performance. It is the responsibility of teachers to help their students advance their ability to achieve their learning goals through feedback.

\subsection{Types of Feedback}

Bitchener and Ferris [6] identify two main categories of WCF: direct and indirect feedback. The former is referred to as a type of correction that attracts students' attention to the error and provides a solution to it. That is to say, the teacher identify errors for the students and provides a correction of them. As for the latter, it refers to attracting students' attention to the places of their errors but without correcting them.

\section{i Direct Corrective Feedback}

This can have several forms such as a) cross-outs: it is when the teacher omits any wrong addition from the students original writings, b) rewrites: this is when the teacher rewrites a word, phrase or a sentence, thus giving the correct spelling, structure or form on the students' original writings and c) additions: it is what the teacher adds to the missing items on the students' original writings (e.g. prefix, suffix, article, preposition, word, etc). According to Bitchener and Ferris [6], the direct corrective feedback aims to benefit students by enabling them to edit their writing and perform in a better way in future tasks. Ferris [13] argues that direct corrective feedback is effective in dealing with errors regarding prepositions and other problems of idiomatic lexis. For her, this has many benefits for them in the final stages of the writing process in helping the students to draw their attention on the errors that finally remain in their texts and refer to them in future tasks.

\section{ii Indirect Corrective Feedback}

As defined by Ferris [13], indirective corrective feedback means underlining, circling or highlighting errors committed by students on their original writings, locating these errors but without giving any correction of them. Students have to study their errors and correct them on their own. Simply put, this type of feedback stresses the role of students in understanding and correcting their errors on their own rather than relying on their teachers to be guided to the errors or receiving the corrections. By underlining the writing errors, it is expected from the students to understand that there is a problem that needs 'fixing'. To localise errors, it is possible for the teacher to use underlining, circling or highlighting. It is what the teacher wants to achieve through feedback that determines his/her decision of how explicit the indirect corrective feedback should be.

As a final note in this literature review, it is worth pointing out that even though corrective feedback has been a popular topic recently, teachers (practitioners) perspectives have been fundamentally absent in the published literature [Evans et al., 11]. In other words, there is a need to investigate teacher's beliefs on WCF in various educational contexts. Thus, the current study aims to fill a gap by investigating the teachers' beliefs, classroom practices and the match between these two regarding WCF in an Omani EFL context.

\subsection{The Present Study}

The aim of the current study is to investigate how feedback in writing is carried out by teachers and to compare what teachers think and do regarding feedback. Meanwhile, the researcher is interested in finding out what the students think of WCF, what WCF strategies they favour and how they assess their teachers' feedback practices inside and outside the classroom. Another comparison is to be made between the views of the teachers and those of the students and their implications.

\subsection{The Research Questions}

(a) To what the extent are the teachers' beliefs and practices regarding the provision of WCF on the students' EFL writing aligned?

(b) To what extent do the students' WCF preferences match the teachers' WCF practices?

\section{Methods}

\subsection{The Context of the Study}

The current study took place at the GFP of one of the private universities in Oman. The GFP is an intensive 
language instruction for the students to join before they can join their academic degrees. This foundation year is considered 'year 0 ' in the degree plan, which is not uncommon among higher education institutions because this usually refers to a non-credited course of study that equips students with the necessary skills and knowledge needed for their higher degree studies. The English language in GFP is taught to three levels of students: elementary, preintermediate and intermediate.

This study takes place in a natural research setting, with the purpose of describing phenomena (i.e. the writing teachers' beliefs about giving WCF and their actual practices and the students' beliefs and preferences related to WCF and whether the two types of beliefs are aligned or not) as they occur naturally (i.e. while teachers are correcting students papers and while they are teaching writing classes). In addition, being a teacher in the same university and spending a prolonged time in the research setting while collecting data, the researcher is familiar with the research setting and the participants.

Four qualitative research instruments were employed in the study: a teacher semi-structured interviews (to elicit the teachers' beliefs and practices related to WCF), student focus groups (to report the students' preferences related to WCF), unstructured classroom observations (to detect the teachers' actual practices while correcting their students' writings and to see if their beliefs and practices are aligned), and a feedback analysis of the students' texts (to explore the teachers' actual practices of the use of WCF).

\subsection{Sampling}

There were 9 GFP teachers and 75 students who participated in this study. Some criteria were used to select the teacher participants: First, the teachers were all teaching writing at the GFP for at least two years. Second, they were teaching writing for the pre-intermediate and intermediate levels of foundation at the time of undertaking the study. Third, they were all willing to participate in the study. Among the 9 teachers, there were 5 females and 4 males. The participants differed in their age, qualifications, level of experience, their first language and national backgrounds (five Indians, one Sudanese, one Egyptian, one British, one Tunisian).

Table 1. The teacher participants' personal information and education background.

\begin{tabular}{|c|c|c|c|c|c|c|c|}
\hline Teacher & Nationality & Gender & First Language & Age & Qualifications & Teaching Years & The level they teach \\
\hline T 1 & Indian & $\mathrm{F}$ & Hindi & $60 \mathrm{~s}$ & MA in English Literature from India & 30 & INT \\
\hline $\mathrm{T} 2$ & Indian & $\mathrm{F}$ & Malayalam & $40 \mathrm{~s}$ & MA in English from India & 25 & INT \\
\hline $\mathrm{T} 3$ & British & $\mathrm{F}$ & English & $50 \mathrm{~s}$ & MA in ELT from the UK & 35 & PRE \\
\hline $\mathrm{T} 4$ & Egyptian & M & Arabic & $40 \mathrm{~s}$ & MA in TESOL from the UK & 20 & INT \\
\hline T5 & Indian & M & Hindi & $40 \mathrm{~s}$ & MA in English from India & 22 & INT \\
\hline T6 & Indian & $\mathrm{F}$ & Malayalam & $50 \mathrm{~s}$ & $\mathrm{PhD}$ in Sociolinguistics from India & 26 & INT \\
\hline $\mathrm{T} 8$ & Indian & M & Malayalam & $50 \mathrm{~s}$ & MA in Literature from India & 25 & INT \\
\hline T9 & Tunisian & M & Arabic & $40 \mathrm{~s}$ & $\begin{array}{l}\text { BA in English Language and } \\
\text { Literature from Tunisia }\end{array}$ & 20 & PRE \\
\hline
\end{tabular}

$\mathrm{T} 1=$ teacher 1 ; INT=intermediate; $\mathrm{PRE}=$ pre-intermediate; $\mathrm{F}=$ female, $\mathrm{M}=$ male, $\mathrm{BA}=\mathrm{Bachelor}$ of Arts, $\mathrm{MA}=\mathrm{Master}$ of Arts, $\mathrm{PhD}=\mathrm{Philosophy} \mathrm{Doctorate}$.

As for the student participants, the researcher asked the teacher participants to find some volunteering students in their classes and the main criterion used was to have high-achievers, average, and low- achievers among the students (i.e. three different levels).

Table 2. The student participants' personal information and education background.

\begin{tabular}{lllll}
\hline Focus Group Serial Number & Gender & Age Range & Student Number & Nationality \\
\hline G1 & M & $19-21$ & 5 & 2 Sudanese 3 Omanis \\
G2 & F & $19-21$ & 5 & Omanis \\
G3 & F & $19-21$ & 5 & Omanis \\
G4 & F & $19-21$ & 5 & Omanis \\
G5 & F & $19-21$ & 5 & Omanis \\
G6 & F & $19-21$ & 5 & Omanis \\
G7 & F & $19-21$ & 5 & Omanis \\
G8 & F & $19-21$ & 5 & Omanis \\
G9 & F & $19-21$ & 5 & Omanis \\
G10 & F & $19-21$ & 5 & Omanis \\
G11 & INT \\
G12 & M & $19-30$ & 5 & 2 Omanis 3 Egyptians \\
G13 & F & $19-21$ & 5 & Omanis \\
G14 & F & $19-21$ & 5 & Omanis \\
G15 & F & $19-21$ & 5 & Omanis \\
\hline
\end{tabular}

$\mathrm{G}=$ group, $\mathrm{M}=$ male, $\mathrm{F}=$ female, $\mathrm{INT}=$ Intermediate, $\mathrm{PRE}=$ Pre-intermediate 
There were 15 groups of students and each group consisted of 5 members, thus resulting in a total of 75 students. They all accepted to take part in the study voluntarily. The majority of the student participants were Omani, their first language was Arabic and their level of education ranges from pre-intermediate to intermediate (i.e. three pre-intermediate and 12 intermediate groups). There were only three Sudanese and two Egyptians among the student participants.

\subsection{Data Collection}

The researcher observed the teachers' WCF practices before interviewing them so that he would not influence them (this was also based on the researcher's readings in the research methodology literature, such as [Al-Adawi 1, Mubarak 27, Alkhatib 2] and mainly to generate more valid data because if teachers were interviewed first, they might change their practices in the classroom observations or adjust their practices based on the questions and the ideas discussed in the interviews. The researcher observed each of the nine teachers twice, so all in all 18 observations were collected. It was only the feedback classroom sessions that were observed. The duration of the observation ranged from 50 minutes to one hour and 20 minutes. The researcher used an unstructured type where all the details of the WCF class were mentioned (the teacher, the class section, the students' level, the date, the time, the duration, the title of the feedback lesson, the number of observation, and what happened during the feedback session). For the interviews, all the nine teachers were interviewed using the researcher's mobile phone and the encounters took place in the department meeting hall. The duration of interviews varied from 25 to 36 minutes. As a third step, the student focus groups took place in the students' own classrooms when there was no class. So, at the end of the lesson, only the group of students who expressed their willingness to participate in the study remained in the class, whereas the teachers and the rest of the students left. The discussions were audio recorded using the researcher's mobile again after getting the students' consent. The duration of the focus group interviews varied from 15 minutes to 24 minutes.

The last instrument used by the researcher was a student text analysis. Having asked the help of the teacher participants to collect sample student writing portfolios from the two levels (pre-intermediate and pre-intermediate) of students selected for the study, hopefully the researcher received a good number of portfolios (54). The nine participant teachers were told to collect from their sections (i.e. classes they taught) writing portfolios from three different types of students: high-achievers, average, and low-achievers. This is to ensure that all the students are represented in the samples and to avoid being biased in the selection of portfolios. The teachers collected their students' writing texts which were obtained from their writing portfolios. All the portfolios included weekly practice paragraphs and essays, first and second draft assessment papers (i.e. continuous assessment writing quizzes). Some criteria were followed by the researcher to select students' writing texts: first the text had to be a paragraph or an essay; second, it should be a practice paper or assessment one; third, there should be a mixture of writing practice texts, writing assessment first draft texts as well as second draft ones. The aim was to assure a variety of texts and more contexts for feedback analysis for all teachers in different scenarios.

\subsection{Data Analysis}

In order to analyse the interview and the focus group data, the researcher used thematic analysis as the analytic lens to interpret the data collected. The thematic analysis is "a method for identifying, analysing, and reporting patterns (themes) within the data" [7]. As for the observation data collected, were handled in the same way as the teacher and student focus group interview transcribed data. In other words, for consistency and validity purposes, the same codes and subcodes were used in order to extrapolate information to answer the research questions. Concerning the fourth research instrument, which is the student text analysis, given that the researcher had 54 portfolios he proceeded by selecting sample writing texts from the portfolios in order to further analyse the teachers' WCF practices. For practical reasons, and because the aim was not to seek representativeness of the sample texts since the current research was primarily qualitative in nature and was merely a case study, the researcher decided to analyse only 10 texts from each of the nine teachers and the sample texts involved sample practice paragraphs and essays, first draft and second draft assessment papers since students had only two assessments during the whole semester. Final exam papers were not considered in the selection of texts. In so doing, 90 texts were obtained from the process of random selection from the students' portfolios. The criteria used by the researcher to select texts were the following: first the text had to be a paragraph or an essay; second, it should be a practice paper or assessment one; third, there should be a mixture of writing practice texts, writing assessment first draft texts as well as second draft ones. This was to assure a variety of texts and more contexts for feedback analysis for all teachers in different scenarios; hence the analysis would be comprehensive and would take different angles or aspects of the portfolio and not focus on one element only.

\section{Results}

\subsection{The Teachers' Beliefs and Practices Regarding WCF}

The first WCF aspect to start with is the identification of errors. In fact, most of the teachers believed that underlining alone is not good; it should be followed by error codes.

"I would never underline and just leave it there. My students need to be equipped with the correction codes. They need to understand what do I mean when I underline... So, just underlining according to me is very misleading and 
confusing for the students. I would never do that."

As demonstrated by the teachers' WCF practices, most teachers used underlining or circling, and error coding. Thus, the teachers' beliefs and actual practices are aligned in this WCF feature.

The second WCF aspect to consider is the correction of errors. According to the findings related to the teachers' beliefs, half of the teachers believed in the importance of correcting errors

"not all the time, yeah, if it is a big one, yes, I have to comment on that"

while the other half did not do so.
"I give the students the corrections code, they have that in front of them, so I use that all the time, so they got some ideas to what the error is. But I do not provide the correct answer for them... (laughs) because I want them to guess, that's the best way to learn, learning from their mistakes, it makes them think, yeah."

The teachers' practices demonstrated that most teachers elicited error correction from the students first, then they had a whole class error correction and the minority of teachers corrected very few errors. Therefore, there seems to be some consistency between the teachers' beliefs and practices.

Table 3. The number of errors corrected by the nine teachers.

\begin{tabular}{|c|c|c|c|c|c|c|c|c|c|}
\hline Number of errors corrected & 40 & 58 & 28 & 14 & 14 & 77 & 33 & 7 & 1 \\
\hline Teachers & $\mathrm{T} 1$ & $\mathrm{~T} 2$ & T3 & $\mathrm{T} 4$ & T5 & T6 & $\mathrm{T} 7$ & $\mathrm{~T} 8$ & T9 \\
\hline
\end{tabular}

$\mathrm{T}=$ Teacher

Another WCF feature is the writing of praising comments on the writing drafts. As indicated by the teachers' beliefs, praising is a very good technique which is essential and is considered as a kind of reward and encouragement. For them, it boosts confidence and leads to improvement for the students. It is also good for self-esteem.

"I think it's a very good technique... I show them a lot of improvement until last writing, well done, keep up this work, em, spelling really improved, good grammar structures used, I am proud of your vocab, sometimes if the work is really good, with few correction errors, for a day I will put it on the board, that's a praise for the student and I tell them have a look, this is what I want"

However, the observation and the text analysis findings revealed the opposite of what the teachers believed in. It is only one third of the teachers who put praising comments on the students' writing drafts. The other third of teachers only mentioned very few praising comments, and the rest did not convey praising comments to students at all. Thus, this feedback aspect is a matter of misalignment between the teachers' beliefs and practices.

Table 4. The number of praising comments written by the nine teachers on the student drafts.

\begin{tabular}{|c|c|c|c|c|c|c|c|c|c|}
\hline Number of praising comments & 5 & 9 & 1 & 1 & 1 & 4 & $\mathbf{0}$ & $\mathbf{0}$ & 30 \\
\hline Teachers & T1 & $\mathrm{T} 2$ & T3 & $\mathrm{T} 4$ & T5 & T6 & $\mathrm{T} 7$ & T8 & T9 \\
\hline
\end{tabular}

$\mathrm{T}=$ Teacher

The fourth WCF feature refers to the amount of feedback. When interviewed, four teachers expressed their interest in providing a selective feedback rather than a comprehensive one in order not to overwhelm the students and demotivate them and even distract them with lots of feedback.

"not everything, you can't be really correcting everything, for example, if there is a mistake that is recurring, rather than correcting it in ten different papers, I'll pick one example and put it on the board and do a whole class feedback on error correction and then I make the student go back to their papers and refer if they have similar, then it becomes easy because I have done something which is there from one of the papers or something similar"

Three other teachers found comprehensive feedback more appropriate because it would enable the students to learn from their mistakes. For them, it is compulsory to follow the marking rubrics that are imposed by the university policies.

"all those aspects I would look into, I would look at content, organisation, cohesion, coherence, spelling, all. But then I won't be underlining all the mistakes because as I told you before if you underline the mistakes here, it depends on how many mistakes they make, you know, some students make only three or four mistakes, and for them ok you can underline all, because there are only three, but if have the whole essay with let us say 25 to 30 spelling mistakes, content, organisation everything sometimes, all those different instead of underlining all the mistakes, I would highlight some mistakes but then I would write my general comments."

The rest of the teachers believed in the variation of the amount of feedback.

"Like I told you from the very beginning, I start with the basic...then gradually I will be moving up... it varies accordingly"

The observations and the text analysis data, however, showed the use of a comprehensive feedback by most of the teachers (seven) but this was only implemented in the assessment papers not for the practice ones. The rest of the teachers (two) used a selective feedback. Consequently, this is also another area of mismatch between the beliefs and practices of the teachers. 
Table 5. The Feedback points (including comments) made by the nine teachers on the 90 student texts.

\begin{tabular}{lllllll}
\hline & Task Achievement & Organisation & Lexis & Grammar \& Mechanics & Comments & Total \\
\hline T1 & 1 & 5 & 34 & 70 & 7 & 117 \\
T2 & 1 & 1 & 20 & 110 & 19 & 14 \\
T3 & 4 & 2 & 45 & 123 & 17 & 181 \\
T4 & 2 & 1 & 53 & 73 & 71 & 14 \\
T5 & 9 & 6 & 70 & 78 & 76 & 184 \\
T6 & 0 & 0 & 6 & 123 & 21 & 136 \\
T7 & 5 & 0 & 24 & 113 & 19 & 163 \\
T8 & 4 & 5 & 125 & 158 & 45 & 311 \\
T9 & 13 & 21 & 49 & 78 & 206 \\
\hline
\end{tabular}

$\mathrm{T}=$ teacher

As for the fifth WCF aspect, it is related to the explicitness of feedback. Regarding the teachers' beliefs, five teachers favoured the use of a mixture of direct and indirect feedback,

"I use a mixture of both... eee, that depends on the purpose of the assessment or the practice you are doing. Sometimes you need to give direct instruction to the student or direct feedback to them because, eee, the type of error itself needs a direct instruction from you to the student, and sometimes there is another type of feedback that may be embarrassing for the student or maybe you have told the student about it before, so you don't have to repeat and give it direct to them, so you can use the indirect way and a student will understand and you will avoid embarrassing them." whereas the rest of them (four) preferred using an indirect feedback only.

"probably mostly indirect... because again this idea of sort of learning from their mistakes... get them to think, and obviously if they don't know perhaps a student will come, because I'll give them time to look at their homework and look at the errors and see if they can work it out and if they ask me what it the right word here or whatever and if they really don't know then obviously I have to tell them (laughs)"

In contrast, it was found through the observations and the text analysis that nearly all the teachers (eight) used an indirect and coded feedback. In this sense, the teachers' beliefs and practices are misaligned another time.

Table 6. The distribution of the explicitness of the teachers'feedback (direct/indirect) on the 90 student texts.

\begin{tabular}{|c|c|c|c|c|c|c|c|c|c|c|}
\hline \multirow[b]{2}{*}{ Teachers } & \multicolumn{2}{|c|}{ Task Achievement } & \multicolumn{2}{|c|}{ Organisation } & \multicolumn{2}{|l|}{ Lexis } & \multicolumn{2}{|c|}{ Grammar and Mechanics } & \multirow{2}{*}{$\begin{array}{l}\text { Total } \\
\text { Dir } \\
\end{array}$} & \multirow{2}{*}{$\begin{array}{l}\text { Total } \\
\text { Ind }\end{array}$} \\
\hline & Dir & Ind & Dir & Ind & Dir & Ind & Dir & Ind & & \\
\hline $\mathrm{T} 1$ & $0(0 \%)$ & $1(1 \%)$ & $0(0 \%)$ & $5(5 \%)$ & $0(0 \%)$ & $34(34 \%)$ & $10(100 \%)$ & $60(60 \%)$ & $10(10 \%)$ & $100(90 \%)$ \\
\hline $\mathrm{T} 2$ & $0(0 \%)$ & $1(0.7 \%)$ & $0(0 \%)$ & $1(0.7 \%)$ & $0(0 \%)$ & $20(15.3 \%)$ & $2(100 \%)$ & $108(83 \%)$ & $2(2 \%)$ & $130(98 \%)$ \\
\hline $\mathrm{T} 3$ & $0(0 \%)$ & $4(2.2 \%)$ & $0(0 \%)$ & $2(1.1 \%)$ & $3(100 \%)$ & $42(24.5 \%)$ & $0(0 \%)$ & $123(71.9 \%)$ & $3(1.8 \%)$ & $171(98.2 \%)$ \\
\hline $\mathrm{T} 4$ & $0(0 \%)$ & $2(1.6 \%)$ & $0(0 \%)$ & $1(0.8 \%)$ & $4(57.1 \%)$ & $49(40.1 \%)$ & $3(42.8 \%)$ & $70(57.3 \%)$ & $7(6 \%)$ & $122(94 \%)$ \\
\hline T5 & $0(0 \%)$ & $9(5.5 \%)$ & $0(0 \%)$ & $6(3.7 \%)$ & $0(0 \%)$ & $70(43.4 \%)$ & $2(100 \%)$ & $76(47.2 \%)$ & $2(1.3 \%)$ & $161(98.7 \%)$ \\
\hline T6 & $0(0 \%)$ & $0(0 \%)$ & $0(0 \%)$ & $0(0 \%)$ & $0(0 \%)$ & $6(6.4 \%)$ & $36(100 \%)$ & $87(93.5 \%)$ & $36(27.9 \%)$ & $93(72 \%)$ \\
\hline $\mathrm{T} 7$ & $0(0 \%)$ & $5(3.5 \%)$ & $0(0 \%)$ & $0(0 \%)$ & $0(0 \%)$ & $24(17.2 \%)$ & $3(100 \%)$ & $110(79.1 \%)$ & $3(2.1 \%)$ & $139(97.8 \%)$ \\
\hline $\mathrm{T} 8$ & $0(0 \%)$ & $4(1.3 \%)$ & $0(0 \%)$ & $5(1.7 \%)$ & $0(0 \%)$ & $125(42.8 \%)$ & $0(0 \%)$ & $158(54.1 \%)$ & $0(0 \%)$ & $292(100 \%)$ \\
\hline T9 & $0(0 \%)$ & $13(8 \%)$ & $0(0 \%)$ & $21(13 \%)$ & $0(0 \%)$ & $49(30.5 \%)$ & $0(0 \%)$ & $78(48.4 \%)$ & $0(0 \%)$ & $161(100 \%)$ \\
\hline
\end{tabular}

$\mathrm{T}=$ teacher, Dir=Direct, Ind=Indirect

The last point in the comparison of the teachers' WCF beliefs and practices concerns the focus of feedback. As noted by the teachers' beliefs, most of the teachers (five) stated that the feedback focus was laid on one area of writing each time.

"what I usually do is sometimes I focus on one area of writing, for example, organisation, paragraph organisation or punctuation and, em, using the mechanics or devices and so on and so on, well it's not on the paragraph level actually, yeah, in that case I focus on that particular area, but at the final writing task, which is writing the paragraph or the essay, I focus on everything I have to do all the mistakes."
They justified this by the fact that if all areas were emphasised on, it would be intimidating for the students. It would also make the students depend solely on the teacher. The rest of the teachers (four) reported that it was essential to focus on everything, especially in assessments drafts, because if not all mistakes were not corrected, there would be gaps remaining in the students' papers. The observations and the text analysis, however, revealed that most of the teachers' (five) emphasis was laid on all aspects of writing, whereas four teachers focused only on grammar and spelling. This WCF aspect can be considered as another area where the teachers' beliefs and practices are not aligned. 
Table 7. The areas on which the nine teachers focused in their feedback on the 90 student texts.

\begin{tabular}{llllll}
\hline Teachers & Task Achievement & Organisation & Lexis & Grammar and Mechanics & Total Points \\
\hline T1 & $1(0.9 \%)$ & $5(4.5 \%)$ & $34(30.9 \%)$ & $70(63.6 \%)$ & 110 \\
T2 & $1(0.7 \%)$ & $1(0.7 \%)$ & $20(15.1 \%)$ & $110(83.3 \%)$ & 132 \\
T3 & $4(2.2 \%)$ & $2(1.1 \%)$ & $45(25.8 \%)$ & $123(70.6 \%)$ & 174 \\
T4 & $2(1.5 \%)$ & $1(0.7 \%)$ & $53(41 \%)$ & $73(56.5 \%)$ & 129 \\
T5 & $9(5.5 \%)$ & $6(3.6 \%)$ & $70(42.9 \%)$ & $78(47.8 \%)$ & 163 \\
T6 & $0(0 \%)$ & $0(0 \%)$ & $6(4.6 \%)$ & $123(95.3 \%)$ & 129 \\
T7 & $5(3.5 \%)$ & $0(0 \%)$ & $24(16.9 \%)$ & $113(79.5 \%)$ & 142 \\
T8 & $4(1.3 \%)$ & $5(1.7 \%)$ & $125(42.8 \%)$ & $158(54.1 \%)$ & 292 \\
T9 & $21(13 \%)$ & $49(30.4 \%)$ & $78(48.4 \%)$ & 161 \\
\hline
\end{tabular}

$\mathrm{T}=$ teacher

\subsection{The Students' WCF Preferences in Comparison with the Teachers' Actual Practices}

Comparing the students' preferences and the teachers' actual practices

The first WCF aspect to start with is the focus of feedback. As revealed by the findings, nearly all the students preferred to have their teachers' feedback on all areas of writing (organisation, grammar, content/ideas, mechanics, and lexis).

"all is important. These are all mentioned in the marking rubrics, so they are all important... when the teacher focuses just on one area we will have problems in the other areas on which he/ she doesn't focus on, so the teacher needs to focus on all of these things, all types of mistakes, this is beneficial for us".

This partly contradicted with the feedback practices observed in the teachers' classes and the ones documented in the students' texts as not all teachers focused on everything in the students' papers. Some teachers focused on everything, while others focused on grammar and spelling only. Thus, this is an example of incongruence between the students' preferences and their teachers' practices.

The second aspect of WCF is related to the explicitness of feedback. The majority of the students preferred indirect and coded feedback.

"All together, so that you know your mistakes and next time you will not do them again... he can only put the comments and from these, the student knows how to correct them, we don't want ready-made corrections"

"If the teacher corrects the mistakes, the students will not learn and benefit from that, so he/she should give comments and let the student correct the mistakes"

This is consistent with the teachers' practices according to which most teachers used indirect and coded feedback.

Another aspect of WCF refers to the amount of feedback. According to the preferences of most of the students, all the mistakes should be identified.

"All, so that he will not do them again, because if he gives just part of them, the student can commit those mistakes which were not identified in the first time"

"Yes all of them, because we shall know their corrections, and like that we will improve"

"All of the mistakes, so that we know our mistakes so that we can correct ourselves and thus we can improve"

This is also another area of alignment with the teachers' practices since the majority of them used a comprehensive type of feedback, especially in assessments.

As for the fourth feature of WCF, which is the correction of errors, the findings showed that most of the students did not want their errors to be corrected.

"We want them all together, except correcting the mistakes. We want to the teacher to underline, use symbols and comments only"

"We don't want the teacher to provide us with corrections... and also comments"

On the other hand, according to the teachers' practices, most teachers corrected very few errors, but some of them did not make any corrections at all. This is an area of partial alignment between the students' preferences and the teachers' practices.

The fifth WCF aspect concerns the writing of praising comments. For most of the students, being praised by their teachers is highly appreciated and preferred.

"it's always negative but only sometimes he adds positive ones...it's demotivating and discouraging for students"

"no positive comments at all"

However, the teachers' practices indicated differences among them. As a matter of fact, the findings revealed that one third of the teachers fairly used praising comments, another third of them made praising comments but not enough and the rest did not do so at all. So, this is another instance of misalignment between what the students expected and what the teachers did in class.

The next aspect of WCF to consider is the source of feedback. The students were asked to choose between teacher and peer feedback and it was found that the majority of the students (13 groups) opted for the teacher feedback.

"We prefer the teacher's feedback because he has more experience and knowledge"

"The teacher because he knows more and has more experience"

"The teacher, because he has more experience and expertise in writing and feedback".

Therefore, it can be said that there is a general alignment between what the students preferred and what the teacher did with respect to this point.

\section{Discussion}

The researcher will now address each research question in 
light of the findings.

RQ1 To what the extent are the teachers' beliefs and practices regarding the provision of WCF on the students' EFL writing aligned?

The collected data showed a number of mismatches between the teachers' beliefs and practices in five WCF areas: the writing of praising comments, redrafting, the amount of feedback, the explicitness of feedback and the focus of feedback. These findings corroborate Lee's [23] study results where several areas of incongruence were identified between teachers' beliefs and practices including the focus of feedback, the explicitness of feedback, the amount of feedback, and positive feedback.

To start with the inconsistency between the teachers' claims and practices in relation to praising, this finding corroborates Lee's [23] study findings which report that the teachers mainly stress the weaknesses in student writing despite their awareness that feedback should cover areas of strengths and weaknesses equally. This is also in line with Alkhatib's [2] study which showed that teachers do not often motivate the high- and average- achievers and haven't motivated on any occasion low-achieving ones through praising their writing. They often used punitive terms with low-achieving students. For the present study, not writing enough positive feedback by the teachers can be explained by their concern with the areas of problems and weaknesses that students have. Another possible reason is the overload of duties they have as well as the time constraints in which they are working.

For the mismatch identified between the teachers' beliefs and practices regarding redrafting, this phenomenon seems to be problematic among the teachers. The data suggest that the teachers' beliefs were not reflected in their practices. This can be explained by the same abovementioned reasons.

The third example of inconsistency between the teachers' beliefs and practices is the amount of WCF. The observations and the feedback analysis suggest that the teachers were using a comprehensive feedback, whereas in the self-reported practices they claimed using a selective feedback. This finding contradicts Alkhatib's [2] research where all teachers supported the comprehensive approach as it would meet the students' expectations and prevent the error fossilisation that may occur if some errors were not corrected. The current study's findings are also in incongruence with those of Jodaie and Farrokhi's [21] research which demonstrated that teachers favoured the comprehensive approach, believing that when there was a great amount of feedback, this would motivate students, whereas when there was little feedback, this would make students depressed.

Another aspect of WCF where the teachers' beliefs and practices were contradictory is the explicitness of feedback. In terms of beliefs, most of the teachers prefer the use of a mixture of direct and indirect feedback, whereas the rest of them (four) preferred using an indirect feedback. According to their actual practices, however, they used indirect and coded feedback. This finding is in agreement with Ferris et al. [15] and Lee [22-23]. Such a belief also seems to be in line with Bitchener and Ferris [6], who argued that when we provide a mixture of direct and indirect feedback, this is considered as the most effective way to scaffold the students' learning and understanding of feedback. On the other hand, the teachers' tendency of using both techniques (direct and indirect) despite their support of the direct method does not corroborate Lee's [24] study finding that teachers tended to apply direct feedback although they favour the indirect approach.

The last example of inconsistency between the teachers' WCF beliefs and practices is the focus of feedback. The majority of the teachers thought that it would be appropriate to vary their focus of feedback each time while the rest of their colleagues favoured the focus on all aspects of writing. However, their actual practices showed that some teachers focused on all aspects of writing and others focused only on language, accuracy and mechanics. This finding is accordance with Alkhatib's [2] study findings which indicate that the teachers were divided regarding their beliefs and practices related to the focus of WCF, thus having six of them who think that organisation should be the primary focus of feedback, while the remaining four of them support the superiority of language form.

Despite the above mentioned mismatches between the teachers' beliefs and practices, there are two instances of consistency, which are error identification and error correction. For error identification, this is in line with Lee's [24] research where the teachers' practices and beliefs were aligned regarding the provision of coded WCF as well as Mao and Crosthwaite's [25] study where the teachers mentioned the importance of using codes in both the teacher questionnaires and interviews, with the feedback analysis of their WCF provision showing that error codes can be found in almost every assignment, despite the teachers in both Lee's and Mao and Crosthwaite's study having doubts regarding the students' ability to make revisions using error codes.

As for the finding related to error correction, teachers do not correct all errors on the student papers because they think that correcting errors for them does not benefit them, thus some teachers make very few corrections on the paper and others do not correct at all. It is also worth pointing out that most teachers elicit error correction first from students then they hold a whole class correction. This is line with Lee's [24] research study showing that teachers locate errors for their students and correct them although they have a firm belief that it is only through teacher feedback that students can learn to correct and locate their own errors. The present study finding related to error correction is also in consistency with Mao and Crosthwaite's [25] study findings revealing that the teachers provided much more indirect feedback than direct feedback, with individual practice seen to be determined by whether the teachers believed they or the students were responsible for learning.

RQ2 To what extent do the students' WCF preferences match the teachers' $W C F$ practices?

Four aspects of WCF can be considered as areas of alignment between the students' preferences and the teachers' 
practices which are the explicitness of feedback, the amount of feedback, and the source of feedback, and the correction of errors. However, there were two areas of misalignment, which are the focus of the feedback and the writing of praising comments.

To start with the first case of alignment, the findings related to the explicitness of feedback do not corroborate Alkhatib's [2] study which suggested that students wanted and expected their teacher to correct their errors explicitly. It also contradicted most L2 studies [15, 11, 22, 3] which argued that students favoured the explicit (i.e., the direct) feedback and not the indirect one. Students in this study were satisfied with their teachers' practices as they tended to use the indirect and coded feedback. One justification can be given for the teachers' use of an indirect and coded feedback lies in the fact that teachers attributed their use of indirect feedback to time constrains and to the students' discontent with the amount of feedback. This explanation is consistent with Ferris [13] who argued that locating errors directly could be "cumbersome for the teacher and confusing for the student".

Concerning the second example of alignment, which is the amount of feedback, the findings related to this point are consistent with the most previous studies [11, 15, 22, 17, 3, 28] which showed that students anticipate an entire correction of their errors and that if the teachers do not correct all the errors committed by the students, the teachers might lose their credibility among their students

The third illustration of alignment between the students' preferences and the teachers' practices is the source of feedback. This finding confirms previous studies $[10,26]$ that revealed that students favor teachers' feedback more than students' feedback because of the following two reasons: a) the low level of the linguistic abilities of their classmates; $b$ ) the experience and expertise of the teacher as a feedback provider. However, there is another finding in the current study that students preferred teachers' feedback over peer feedback.

The last instance of alignment is the correction of errors. This is an area of partial congruence. Many researchers explored the perceptions of teachers and students concerning error correction and came to the conclusion that there exist many mismatches between them. Ancker [4] examined teachers' and students' expectations toward error correction and the concluded that students expected more error correction than teachers. A third study by Fukuda [16], which focused on teachers' and students' opinions about error treatment, showed that the students wanted more error treatment than their teachers believed.

Apart from the cases of alignment between the students' preferences and the teachers' practices regarding WCF, there are two areas of misalignment. The first case is related to the focus of the feedback. The finding related to this WCF aspect conflicts with Alkhatib's [2] study where students believed that it is more important to focus on errors related to content rather than those related to form. This finding related to the focus of feedback further indicated three things: a) it is probable that the teachers had no idea about their students' needs and preferences; b) maybe they sometimes have a wrong perception of those needs and preferences; c) there might be no enough communication between the teachers and the students regarding this issue. Moreover, it is worth adding that despite the fact that teachers' practices regarding the focus on language form were not supported by their beliefs nor by their students' preferences, it might be the case that teachers find themselves forced to deal with grammar and mechanics, given the students' low proficiency levels, which -according to the present study teachers- constituted one of the biggest constraints in teachers' practices.

The second feature of misalignment is the writing of praising comments. This finding is congruent with Hyland and Hyland [19] who suggested that it is only when feedback motivates the students and gives a great consideration to their individual needs that they most likely consider their teacher's feedback effective.

It can be concluded that the teachers' misperceptions of the students' preferences might account for the mismatch between the teachers' practices and the students' preferences. This confirms some previous studies $[18,11,20]$ which showed some mismatches between teachers' practices and students' preferences. The misalignment between students' preferences and teachers' practices seems to be problematic. Teachers might use a specific kind of feedback in order to meet their students' needs, whereas their students may not accept it. This is the very scenario of the current study. It is reported that the teachers sometimes have the tendency to do what they thought to be effective and appealing for students but it appeared to be demotivating for the students. The students in the interviews expressed their desire to have a comprehensive feedback, but the teachers' actual practices in the observations and the text analysis were contradictory to that. In addition, the students liked their teachers to write positive feedback comments on their papers, but their practices showed the opposite. As argued by Amrhein and Nassaji [3], unless students receive the feedback they want, it is possible that they will not benefit from it. It is pointed out by many studies that to in order to make teachers' WCF more useful, there should be a match between students' preferences and teachers' practices $[11,20]$.

\section{Conclusion}

The first aim of the current study was to explore the relationship between the teachers' beliefs and practices regarding how WCF should be provided on the students' FL writing and the extent to which their beliefs were reflected on their practices. The study revealed more areas of incongruence than congruence between the teachers' beliefs and practices related to WCF. The second aim of the study was to examine the students' preferences against their teachers' WCF beliefs and actual practices. The collected data suggested that there were more areas of alignment than misalignment between the two. There are some important implications for pedagogy and research related to WCF by 
which this paper can be concluded:

1) A student-centred approach to WCF should be launched: the students' views towards feedback can be changed by the teachers, that is to say, the students should be stimulated to play a more active role in the learning-towrite process. For example, students can be trained on peer and self-evaluation and be allowed to take part in the development of assessment criteria for different writing tasks, or given the opportunity to use error frequency charts or error logs to raise their awareness of their own error patterns in order to make them more responsible for their own improvement.

2) Students should be trained on self-editing strategy: This means empowering L2/FL students to become capable of editing their own errors and commenting on their peers' writing when they are trained, guided and motivated to do so. Accordingly, it is the duty of the teachers need find the ways and the means whereby they can enable the students to become independent writers whether in the mid or long term.

3) Positive feedback should be a priority: teachers can explore some strategies to motivate low performing students in writing by including praising comments on their effort, focusing on interesting content, and responding to a considerable amount of errors.

\section{References}

[1] Al-Adawi, H. (2010). A naturalistic context-based study on feedback on Omani EFL undergraduate student writing. [Unpublished doctoral dissertation]. The University of Leeds.

[2] Alkhatib, M. N. (2015). Written corrective feedback at a Saudi university: English language teachers' beliefs, students' preferences, and teachers' practices. [Unpublished doctoral dissertation]. The University of Essex.

[3] Amrhein, H. R. \& Nassaji, H. (2010). Written corrective feedback: What do students and teachers prefer and why? Canadian Journal of Applied Linguistics, 13, 95-127.

[4] Ancker, W. (2000). Errors and corrective feedback: Updated theory and classroom practice. English Teaching Forum, 38 (4), 20-24.

[5] Arrad, G., Vinkler, Y., Aharonov, D., \& Retzker, A. (2014). Increasing sensing resolution with error correction. Physical Review Letters, 112 (15), 150801.

[6] Bitchener, J. \& Ferris, D. R (2012). Written corrective feedback in second language acquisition and writing. New York: Routledge.

[7] Braun, V. \&. Clarke, V. (2006). Using thematic analysis in psychology. Qualitative Research in Psychology, 3 (2), 77-101.

[8] Brookhart, S. M. (2003). Developing measurement theory for classroom assessment purposes and uses. Educational Management: Issues and Practice, 22 (4), 5-12.

[9] Carless, C. (2006). Differing perceptions in the feedback. Studies in Higher Education, 31 (2), 219-233.

[10] Connor, U. M. \& Asenavage, K. (1994). Peer response groups in ESL writing classes: How much impact on revision? Journal of Second Language Writing, 3, 257-276.

[11] Diab, R. L. (2005). EFL university students' preferences for error correction and teacher feedback on writing. TESL Reporter, 38 (1), 27-51.

[12] Evans, N. W., Hartshorn, K. J., \& Tuioti, E. A. (2010). Written corrective feedback: The practitioners' perspective. International Journal of English Studies, 10 (2), 47-77. https://doi.org/10.6018/ijes/2010/2/119191

[13] Ferris, D. R. (2002). Treatment of error in second language writing classes. Ann Arbor, MI: University of Michigan Press.

[14] Ferris, D. R., Pezone, S., Tade, C., \& Tinti, S. (1997). Teacher commentary on student writing: Descriptions and implications. Journal of Second Language Writing, 6, 155-182.

[15] Ferris, D. R., \& Roberts, B. (2001). Error feedback in L2 writing classes: How explicit does it need to be? Journal of Second Language Writing, 10, 161- 184.

[16] Fukuda, Y. (2004). Treatment of spoken errors in Japanese high school oral communication classes. Unpublished Master's thesis, California State University, San Francisco.

[17] Hamouda, A. (2011). A study of students and teachers' preferences and attitudes towards correction of classroom written errors in Saudi EFL context. English Language Teaching, 4 (3), 128-129.

[18] Hyland, K. (2003). Second language writing. Cambridge: Cambridge University Press.

[19] Hyland, K. \& Hyland, F. (2006). Feedback in second language writing: Contexts and issues. Cambridge: Cambridge University Press.

[20] Jeon, M., \& Kang, I. (2005). Investigating student preferences in error correction in Korean-language teaching. The Korean Language in America, 10, 93-112.

[21] Jodaie, M., \& Farrokhi, F. (2012). An exploration of private language institute teachers" perceptions of written grammar feedback in EFL classes. English Language Teaching, 5 (2), $58-69$

[22] Lee, I. (2003). How do Hong Kong English teachers correct errors in student writing? Education Journal, 31 (1), 153-169.

[23] Lee, I. (2008). Understanding teachers' written feedback practices in Hong Kong secondary classrooms. Journal of Second Language Writing, 17 (2), 69-85.

[24] Lee, I. (2009). Ten mismatches between teachers' beliefs and written feedback practice. ELT Journal, 63, 13-22.

[25] Mao, S. \& Crosthwaite, P. (2019). Investigating Written Corrective Feedback: (Mis)alignment of Teachers' Beliefs and Practice. Journal of Second Language Writing, 45, 46-60.

[26] Montgomery, J. L. \& Baker, W. (2007). Teacher-written feedback: Student perceptions, teacher self-assessment, and actual teacher performance. Journal of Second Language Writing, 16, 82-99.

[27] Mubarak. (2013). Corrective feedback in L2 writing: A study of practices and effectiveness in the Bahrain context. [Unpublished doctoral dissertation]. University of Sheffield. 
[28] Norouzian, R. \& Farahani, A. (2012). Written error feedback from perception to practice: A feedback on feedback. Journal of Language Teaching and Research, 3 (1), 11-22.
[29] Paltridge, B. (2004). Approaches to teaching second language writing. 17th Educational Conference, Adelaide. Retrieved from https://celta.wikispaces.com/file/view/Paltridge.pdf/30724017/P altridge.pdf. 